\title{
Carbazole-oxadiazole containing polyurethanes as phosphorescent host for organic light emitting diodes
}

\author{
Cheng-Hsiu Ku ${ }^{\text {a }}$, Chao-Hui Kuo ${ }^{a}$, Man-kit Leung ${ }^{\text {a,c,*, Kuo-Huang Hsieh }}{ }^{\text {a,b,* }}$ \\ ${ }^{a}$ Institute of Polymer Science and Engineering, National Taiwan University, Taipei 10617, Taiwan \\ ${ }^{\mathrm{b}}$ Department of Chemical Engineering, National Taiwan University, Taipei 10617, Taiwan \\ ${ }^{\mathrm{c}}$ Department of Chemistry, National Taiwan University, Taipei 10617, Taiwan
}

\section{A R T I C L E I N F O}

\section{Article history:}

Received 26 August 2008

Received in revised form 26 December 2008

Accepted 20 January 2009

Available online 30 January 2009

\section{Keywords:}

Polymeric light emitting diodes (PLEDs)

Polyurethanes (PUs)

Phosphorescent host

Phosphorescent organic light emitting

diodes (PHOLED)

\begin{abstract}
A B S T R A C T
New types of polyurethanes (PUs) were prepared from condensation polymerization of isophorone diisocyanate (IPDI) with various combination of 9-butyl-3,6-bis(4-hydroxyphenyl)carbazole (Cz) and 2,5-bis(4-hydroxyphenyl)-1,3,4-oxadiazole (OXD), and endcapped with 4-tert-butyl phenol. The Cz-OXD PUs can also be used as host for phosphorescent dye. Red EL emission was obtained when $\operatorname{Ir}(\mathrm{btp})_{2}$ (acac) or $\operatorname{Ir}(2-\mathrm{phq})_{2}(\mathrm{acac})$ was used as the phosphorescent dyes in Cz-OXD (3:1) PU. Maximum brightness of $394 \mathrm{~cd} / \mathrm{m}^{2}$ and EL efficiency of $1 \mathrm{~cd} / \mathrm{A}$ were achieved for the $\operatorname{Ir}(2-\mathrm{phq})_{2}(\mathrm{acac})$ base device. In addition, white light PLED was demonstrated when co-dopant of $\operatorname{Ir}(\mathrm{btp})_{2}(\mathrm{acac})$ and Firpic were used.
\end{abstract}

(c) 2009 Elsevier Ltd. All rights reserved.

\section{Introduction}

Organic small-molecule light emitting diodes (OLEDs) and polymeric light emitting diodes (PLEDs) have been extensively studied since the pioneering work published by Tang [1]. To obtain reasonable light emitting performance, multilayer structures were adopted in which the emissive layer was sandwiched between the hole and electron transport layers [2]. Unlike the multilayer OLEDs, the prototype of PLED was established on the basis of a singlelayer of PPV on ITO [3]. However, the efficiency and brightness of the output was not ideal. Many different factors might affect the PLED performance. Nevertheless, balanced carrier injection and transport properties are important and necessary conditions to achieve high performance devices. MEH-PPV is one of the successful examples [4,5].

\footnotetext{
* Corresponding authors. Present address: Institute of Polymer Science and Engineering, National Taiwan University, No. 1, Sec. 4, Roosevelt Road, Taipei 10617, Taiwan. Fax: +886 23636359 (M.-k. Leung).

E-mail addresses: mkleung@ntu.edu.tw (M.-k. Leung), khhsieh@ntu. edu.tw (K.-H. Hsieh).
}

Similar idea has recently been extended to OLED [6]. Polyurethanes (PUs) have been widely used in industrial applications due to their good properties in good elasticity, flexibility, thermal stability, and excellent chemical resistance [7-12]. In addition, PU conducting polymers have also been developed [13-15]. Recently, applications of PUs on PLED have been reported. It has been demonstrated that PUs could be used as effective hole-transport matrix [16-18] as well as applied for light emitting layers $[19,20]$. Since PUs were usually prepared from condensation polymerization of diols and diisocyanates under metal-ion free conditions, [21] metal-ion contaminants could therefore be minimized. In addition, the adhesion of polar PU on ITO surface is expected to be good. This may benefit for the PLED device fabrication [22,23]. However, perhaps due to the fluorescence quenching effect through hydrogen bonding interactions, only limited numbers of examples about using PU as the light emitting materials were known [24,12]. Carbazole $(\mathrm{Cz})$ derivatives are photoconductors with good hole-transport properties [25-28]. Recently, carbazole derivatives have been used as efficient triplet hosts in phosphorescent OLED (PHOLED) 
$[29,30]$. All these intrigued us to explore the application potentials of carbazole containing PUs on PLED applications. 2,5-Diphenyl-1,3,4-oxadiazole (OXD) and its derivatives are common electron injection and transport materials [31-34] due to their prominent electron affinity, high photoluminescence, and good thermal stability $[35,36]$. Since doping of the electron-deficient components into the hole-transport layer sometimes may improve the performance of the OLED device, [37] we are interested in studying the performance of Cz-OXD copolymers on PLED.

Herein we report the preparation and characterization of novel PUs, named as CX10, CX31, CX11, CX13 and CX01 (Scheme 1). The abbreviation of the polymers indeed reflects the composition of the polymers, in which $\mathrm{C}$ and $\mathrm{X}$ represent carbazole and oxadiazole units, respectively; and the following number represents the feeding ratio of these two components in the PUs. Among the PUs, carbazole based CX10 and the oxadiazole based CX01 were homopolymers and CX31-CX13 were carbazole-oxadiazole based co-polymers. Although PU polymers usually dissolved in polar aprotic solvent such as DMF, this solvent is not completely compatible with PEDOT-PSS, a common water-soluble hole-injection polymer, because the PEDOT-PSS layer would be slightly etched by DMF during multi-step coating process [16]. To make use of the PU solution compatibly with the PEDOT-PSS layer, we have adjusted the alkyl substituent on the PUs, so that the final PUs would have good solubility in a relatively non-polar solvent such as THF.

In this study, we discovered that the PU could be used as host material for red phosphorescent emitter. White

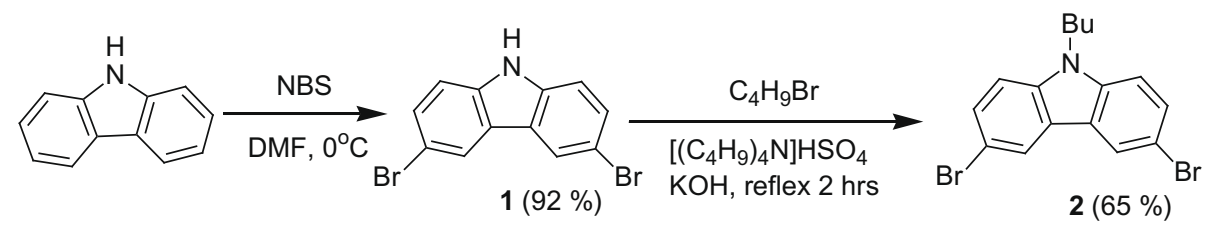<smiles>COc1ccc(-c2ccc3c(c2)c2cc(-c4ccc(OC)cc4)ccc2n3Cc2ccccc2)cc1</smiles><smiles></smiles><smiles>[X]c1ccc2c(c1)c1cc(-c3ccc(O)cc3)ccc1n2Cc1ccc(O)cc1</smiles><smiles>[X]c1ccc(-c2nnc(-c3ccc(OC(=O)NC4CC(C)(C)CC(C)(CNC(=O)OCC)C4)cc3)o2)cc1OC(=O)NCC1(C)CC(NC(=O)Oc2ccc(-c3ccc4c(c3)c3cc(-c5ccc(OC)cc5)ccc3n4Cc3ccc(OC(=O)OCC)cc3)cc2)CC(C)(C)C1</smiles>

Scheme 1. Synthetic routes for 4,5 and CX10-CX01. 
light emitting device has also been fabricated to study. To our knowledge, successful examples of using PU as host for the light emitting layer are rare.

\section{Experimental section}

\subsection{Fabrication of phosphorescent PLED device}

The devices with a standard configuration of ITO/PEDOT-PSS $(30 \mathrm{~nm}) / \mathrm{PU}(30 \mathrm{~nm})-\mathrm{Ir}$ complexes/BCP $(10 \mathrm{~nm}) /$ $\mathrm{Alq}_{3}(40 \mathrm{~nm}) / \mathrm{LiF}(1 \mathrm{~nm}) / \mathrm{Al}(150 \mathrm{~nm})$ were fabricated. ITO plates were first cut into appropriate sizes and the ITO surface was cleaned by sonication, rinsing in deionized water, Triton-100 water solution, deionized water, acetone and ethanol treatment then dried by a dry nitrogen flow and finally cleaned by oxygen plasma. The PEDOT-PSS solution were prepared by mixing the commercially available PEDOT-PSS solution with diluted Triton-100 solution (5\% in $\mathrm{H}_{2} \mathrm{O}$ ) in a 10: $1(\mathrm{~V} / \mathrm{V})$, spin-coated at a rate of $4000 \mathrm{rpm}$, and dried at $90{ }^{\circ} \mathrm{C}$ for $30 \mathrm{~min}$ under vacuum. After then, the emitting polymer layers $(2000 \mathrm{rpm}, 30 \mathrm{~nm})$ were spin-coated from a solution of Ir complex $(4 \mathrm{mg})$ and CX31 (46 mg) in THF (2 mL) on top of the PEDOT-PSS layer at a spinning rate of $4500 \mathrm{rpm}$. The layer was baked $\left(50{ }^{\circ} \mathrm{C}\right.$ for $10 \mathrm{~min}$ ), followed by thermal vacuum evaporation of a layer of 2,9-dimethyl-4,7-diphenyl-1,10-phenanthroline $(\mathrm{BCP})(10 \mathrm{~nm})$, and $\mathrm{Alq}_{3}(40 \mathrm{~nm})$ at pressure below $5 \times 10^{-6}$ torr with deposition rate of $3 \AA / \mathrm{s}$. The LiF and $\mathrm{Al}$ contacts were finally deposited under the same vacuum conditions. The deposition rates for $\mathrm{LiF}$ and $\mathrm{Al}$ cathodes were 1 and $4 \AA / s$, respectively. The thickness of each layer was calibrated, respectively, by an Alpha step instrument.

\subsection{Synthesis of PU's CX10-CX01}

The preparation of the homopolymers CX10 and CX01, and copolymers CX31, CX11, and CX13 were summarized in Scheme 1. The actual ratio of the carbazole/oxadiazole units in the copolymers were determined by ${ }^{1} \mathrm{H}$ NMR (Fig. 1). The data were summarized in Table 1 and described as follows.

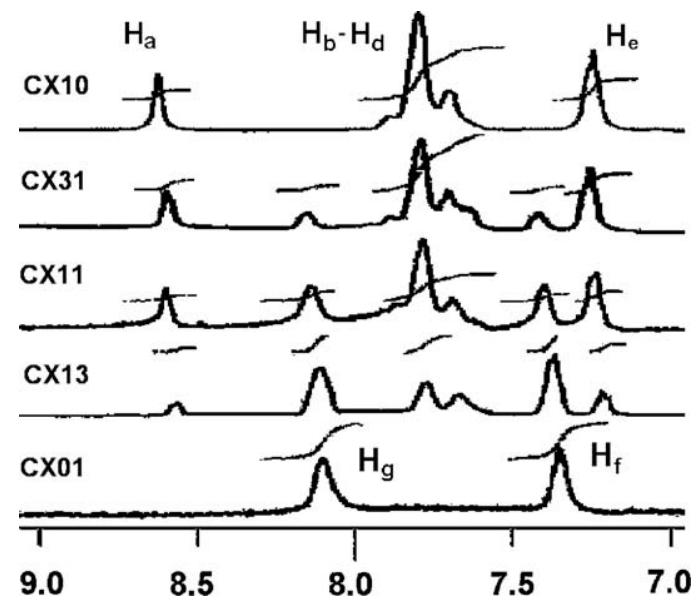

Fig. 1. The ${ }^{1} \mathrm{H}$ NMR spectra of CX10-CX01.

\subsection{1. $C X 10$}

A typical procedure: To a two-necked round bottom flask (50 mL), equipped with a magnetic stir under nitrogen, was loaded a solution of 9-butyl-3,6-bis(4-hydroxyphenyl)carbazole (4) $(2.04 \mathrm{~g}, 5.0 \mathrm{mmol})$, isophorone diisocyanate (1.16 g, $5.25 \mathrm{mmol})$, and dried DMF (25 mL). After reaction for $24 \mathrm{~h}, 4$-tert-butylphenol $(0.075 \mathrm{~g}$, $0.5 \mathrm{mmol}$ ) was injected into the reaction mixture as the terminating agent. The reaction was further reacted for another $24 \mathrm{~h}$. When reaction was completed, the polymer was precipitated by drop-wise addition of the reaction mixture into methanol. The polymer was redissolved in DMF and re-precipitated in $\mathrm{MeOH}$ for at least 5-10 times in order to obtain an essentially pure sample. The PU was collected and washed with toluene and chloroform to remove any DMF. The final PU was collected and dried under vacuum conditions for about $12 \mathrm{~h}$ at $100-105^{\circ} \mathrm{C}(2.85 \mathrm{~g}$, 50\%): Anal. Calcd based on the calibrated composition listed in Table 1: CX10: C, 74.4; H, 6.7; N, 6.5\%. Found: C, 72.9; $\mathrm{H}, 7.4 ; \mathrm{N}: 7.4 \%$; ${ }^{1} \mathrm{H}$ NMR $\left(400 \mathrm{MHz}, \mathrm{DMSO}-d_{6}\right) \delta$ 8.4-8.6 (bs, 2H, $\left.\mathrm{H}_{\mathrm{a}}\right), 8.0-7.5\left(\mathrm{~m}, 8 \mathrm{H}, \mathrm{H}_{\mathrm{b}}, \mathrm{H}_{\mathrm{c}}\right.$, and $\mathrm{H}_{\mathrm{d}}$ on carbazole), 7.3-7.1 (bs, 4H, $\mathrm{H}_{\mathrm{e}}$ ), 4.4-4.3 (bs, $2 \mathrm{H}, \mathrm{N}-\mathrm{CH}_{2}-$ ), 1.80.7 ( $\mathrm{m}, 25 \mathrm{H}$, alkyl protons).

\subsection{2. $C X 31(55 \%)$}

When reaction was completed, the polymer was precipitated by drop-wise addition of the reaction mixture into methanol. The polymer was re-dissolved in DMF and reprecipitated again in $\mathrm{MeOH}$ for several times, followed by precipitation in $\mathrm{MeOH} / \mathrm{H}_{2} \mathrm{O}=4: 1$. The collected PU was finally washed with toluene and chloroform to remove residual DMF. Anal. Calcd based on the calibrated composition listed in Table 1. (Cz) $74.7-(\mathrm{OXD})_{25.3}: \mathrm{C}, 72.0 ; \mathrm{H}, 6.4 ; \mathrm{N}$, 7.7\% Found: C, 71.5.; H, 7.4; N, 7.5\%. ${ }^{1} \mathrm{H}$ NMR $(400 \mathrm{MHz}$, DMSO- $\left.d_{6}\right) \delta 8.7-8.5$ (bs, $\mathrm{H}_{\mathrm{a}}$ ), 8.11-8.13 (bs, $\mathrm{H}_{\mathrm{g}}$ ), 8.05-7.60 $\left(\mathrm{m}, \mathrm{H}_{\mathrm{b}}, \mathrm{H}_{\mathrm{c}}\right.$, and $\left.\mathrm{H}_{\mathrm{d}}\right), 7.4-7.3$ (bs, $\mathrm{H}_{\mathrm{f}}$ ), 7.2-7.1 (bs, $\left.\mathrm{H}_{\mathrm{e}}\right), 4.5-$ 4.4 (bs, $\mathrm{N}-\mathrm{CH}_{2}-$ ), $1.7-0.8$ ( $\mathrm{m}$, alkyl-protons). The ratio of 2.96/1.00 for the carbazole/oxadiazole units was determined by their integrations at $\delta 7.2-7.1$ and 7.4-7.3.

\subsubsection{CX11 (40\%)}

When reaction was completed, the polymer was precipitated by drop-wise addition of the reaction mixture into methanol. The polymer was re-dissolved in DMF and reprecipitated again in $\mathrm{MeOH}$ for several times, followed by precipitation in $\mathrm{MeOH} / \mathrm{H}_{2} \mathrm{O}=3: 1$. The collected PU was finally washed with toluene and chloroform to remove residual DMF. Anal. Calcd based on the calibrated composition listed in Table 1. $(\mathrm{CZ})_{52.3}-(\mathrm{OXD})_{47.7}: \mathrm{C}, 69.1 ; \mathrm{H}, 6.3 ; \mathrm{N}$, 8.8\%. Found: C, 69.2.; H, 6.9; N: 9.7\%. ${ }^{1} \mathrm{H}$ NMR (400 MHz,

Table 1

Compositions of CX10-CX01 by ${ }^{1} \mathrm{H}$ NMR.

\begin{tabular}{llll}
\hline PU & Integration & Ratio \\
\cline { 2 - 3 } & Carbazole at $\delta 7.1-7.2$ & OXD at $\delta 7.3-7.4$ & \\
\hline CX10 & 1 & 0 & \\
CX31 & 2.009 & 0.679 & $2.96 / 1.00$ \\
CX11 & 1.452 & 1.305 & $1.11 / 1.00$ \\
CX13 & 0.355 & 0.995 & $1.00 / 2.80$ \\
CX01 & 0 & 1 & \\
\hline
\end{tabular}


DMSO- $\left.d_{6}\right) \delta 8.6-8.5\left(\mathrm{bs}, \mathrm{H}_{\mathrm{a}}\right.$ ), 8.4-8.2 (bs, $\left.\mathrm{H}_{\mathrm{g}}\right), 8.05-7.60(\mathrm{~m}$, $\mathrm{H}_{\mathrm{b}}, \mathrm{H}_{\mathrm{c}}$, and $\mathrm{H}_{\mathrm{d}}$ ), 7.4-7.3 (bs, $\mathrm{H}_{\mathrm{f}}$ ), 7.2-7.1 (bs, $\mathrm{H}_{\mathrm{e}}$ ), 4.5-4.4 (bs, $\mathrm{N}-\mathrm{CH}_{2}-$ ), 1.7-0.5 (m, alkyl-protons). The ratio of $1.11 / 1.00$ for the carbazole/oxadiazole units was determined by their integrations at $\delta 7.2-7.1$ and 7.4-7.3.

\subsection{4. $C X 13(60 \%)$}

When reaction was completed, the polymer was precipitated by drop-wise addition of the reaction mixture into methanol. The polymer was re-dissolved in DMF and re-precipitated again in $\mathrm{MeOH}$ for several times, followed by precipitation in $\mathrm{MeOH} / \mathrm{H}_{2} \mathrm{O}=1: 1$. The collected PU was finally washed with toluene and chloroform to remove residual DMF. Anal. Calcd based on the calibrated composition listed in Table 1. $(\mathrm{Cz})_{26.3}-(\mathrm{OXD})_{73.7}$ : C, 66.3; H, 5.9; N, 10.1\% Found: C, 67.8.; H, 6.6; N, 9.9\%. ${ }^{1} \mathrm{H}$ NMR (400 MHz, DMSO- $d_{6}$ ) 8.7-8.6 (bs, $\mathrm{H}_{\mathrm{a}}$ ), 8.3-8.2 (bs, $\mathrm{H}_{\mathrm{g}}$ ), 7.8-7.5 ( $\mathrm{m}, \mathrm{H}_{\mathrm{b}}, \mathrm{H}_{\mathrm{c}}$, and $\left.\mathrm{H}_{\mathrm{d}}\right), 7.4-7.3$ (bs, $\mathrm{H}_{\mathrm{f}}$ ), 7.2-7.1 (bs, $\mathrm{H}_{\mathrm{e}}$ ), 4.5-4.4 (bs, $\mathrm{N}-\mathrm{CH}_{2}-$ ), 1.7-0.5 (m, alkyl-protons). The ratio of $1.00 / 2.80$ for the carbazole/oxadiazole units was determined by their integrations at $\delta 7.2-7.1$ and 7.4-7.3.

\subsubsection{CX01 (45\%)}

When reaction was completed, the polymer was precipitated by drop-wise addition of the reaction mixture into methanol. The polymer was re-dissolved in DMF and reprecipitated again in $\mathrm{MeOH}$ for several times, followed by precipitation in $\mathrm{MeOH} / \mathrm{H}_{2} \mathrm{O}=1: 1$. The collected PU was finally washed with toluene and chloroform to remove residual DMF. Anal. Calcd based on the calibrated composition listed in Table 1. CX01: C, 63.40; H, 5.73; N, 11.38\% Found: C, 63.3; H, 6.4; N, 11.3\%. ${ }^{1} \mathrm{H}$ NMR (400 MHz, DMSO- $\left.d_{6}\right) \delta 8.3-8.1$ (bs, 4H, $\mathrm{H}_{\mathrm{g}}$ ), 7.5-7.3 (bs, 4H, $\mathrm{H}_{\mathrm{f}}$ ), 1.5$0.7(\mathrm{~m}, 18 \mathrm{H})$.

\section{Results and discussion}

\subsection{Synthesis of the monomers and the corresponding PUs}

Scheme 1 shows the synthetic pathways for 9-butyl-3,6bis(4-hydroxyphenyl)carbazole (4) and 2,5-bis(4-hydroxyphenyl)-1,3,4-oxadiazole (5). Carbazole 4 was synthesized through a four-step reaction sequence. Bromination of $9 \mathrm{H}-$ carbazole with NBS afforded 3,6-dibromo-9H-carbazole (1) in $92 \%$ yields [38]. Butylation was performed by reacting 1-bromobutane with 1 in the presence of phase transfer agent under basic conditions to give $\mathbf{2}$ in 65\% yield [39]. Suzuki coupling [40] of 2 and $4-\mathrm{MeOC}_{6} \mathrm{H}_{4} \mathrm{~B}(\mathrm{OH})_{2}$ led to 3 . The protective methyl groups were finally removed by treatment with $\mathrm{BBr}_{3}$ to give bisphenol 4 [41].

Monomer 5 was prepared from condensation of 4hydroxybenzoic acid hydrazide with 4-hydroxybenzoic acid phenyl ester [42]. Phenol, the by-product, was removed through distillation. Recrystallization of the crude product from a mixed solution of $\mathrm{N}, \mathrm{N}$-dimethylacetamide and deionized water provided 5 in $45 \%$ yield.

Condensation polymerization of the isocyanate monomer IPDI with $\mathbf{4}$ and $\mathbf{5}$ was performed in dried DMF [4346] and end-capped with 4-tert-butylphenol to afford
CX10-CX01. The polymers were purified by precipitation in $\mathrm{MeOH}$ for several times before use. Their ${ }^{1} \mathrm{H}$ NMR spectra of the aromatic regions were enlarged and shown in Fig. 1.

CX10 showed ${ }^{1} \mathrm{H}$ NMR at $\delta$ 8.4-8.6, a broad singlet which was assigned to $\mathrm{H}_{\mathrm{a}}$. On the other hand, resonance signals showed up at $\delta 8.0-7.5$ were assigned to $\mathrm{H}_{\mathrm{b}}, \mathrm{H}_{\mathrm{c}}$, and $\mathrm{H}_{\mathrm{d}}$. These signals merged to show multiplets with the integration equal to 8 protons. Protons $\mathrm{H}_{\mathrm{e}}$, which are ortho to the electron-donating oxygen atoms, showed up at the relatively up-field region of $\delta 7.3-7.1$ with the integration equal to 4 protons. The $\mathrm{N}-\mathrm{CH}_{2}-$ protons showed up at $\delta$ 4.4-4.3 while other alkyl protons all appeared at $\delta 1.8-0.7$.

On the other hand, CX01 clearly showed two sets of broad ${ }^{1} \mathrm{H}$ NMR signals. One set appeared at $\delta$ 8.3-8.1 were assigned to $\mathrm{H}_{\mathrm{g}}$, which were relatively down-field shifted due to the the presence of the adjacent electron-withdrawing oxadiazole groups. On the other hand, the other set of signals at 7.5-7.3 was assigned to $\mathrm{H}_{\mathrm{f}}$ that were ortho to the electron-donating oxygen atoms.

Copolymers CX31, CX11, and CX13 showed all proton signals arising from the carbazole and oxadiazole units. Their ratios could be simply determined by using the signal integrations at $\delta 7.3-7.1$ and 7.5-7.3 and were summarized in Table 1. The deviation of the NMR ratios from their feeding ratios were small. These results were also consistent with the data of elemental analyses.

\subsection{Physical properties of $C X 10-C X 01$}

The $M_{\mathrm{n}}, M_{\mathrm{w}}$, and PDI values, were determined by gelpermeation chromatography (GPC) in THF against polystyrene standard (Table 2 ). The GPC results were in good agreement with the NMR integrations. Their thermal characteristics, including $T_{\mathrm{d}}$ and $T_{\mathrm{g}}$, were collected with the scanning rate of $20^{\circ} \mathrm{C} / \mathrm{min}$.

The $M_{\mathrm{w}}$ of the PUs were all ranged between 9800 and 6400 , as for the number average molecular weight $\left(M_{\mathrm{n}}\right)$ values of the polymers were in the range of 6600-4600. Although $\mathrm{M}_{\mathrm{w}}$ and $M_{\mathrm{n}}$ were relatively low in comparison to other PLED polymers, the presence of inter-chain hydrogen bonding interactions between the urethane groups allowed high degree of inter-chain entanglement, leading to good film quality from the spin-coating process. This point of view was further proved in the AFM study discussed in latter sections.

The high $T_{\mathrm{g}}$ and $T_{\mathrm{d}}$ of CX10-CX01 reflected their high glassy-state durability and thermal stability. These results

Table 2

Yields, molecular weights, and thermal properties of CX10-CX01.

\begin{tabular}{lllllll}
\hline PU & Yield $(\%)$ & $M_{\mathrm{w}}$ & $M_{\mathrm{n}}$ & PDI & $T_{\mathrm{d}}\left({ }^{\circ} \mathrm{C}\right)^{\mathrm{a}}$ & $T_{\mathrm{g}}\left({ }^{\circ} \mathrm{C}\right)$ \\
\hline CX10 & 50 & 9800 & 6600 & 1.48 & 270 & 178 \\
CX31 & 55 & 6400 & 4600 & 1.41 & 264 & 167 \\
CX11 & 40 & 8400 & 5800 & 1.45 & 257 & 153 \\
CX13 & 60 & 6600 & 4700 & 1.42 & 272 & 146 \\
CX01 & 55 & 7600 & 5600 & 1.36 & 301 & 135 \\
\hline
\end{tabular}

a The $T_{\mathrm{d}}$ point was judged by $5 \%$ weight loss of the polymer. 
were attributed to the inter-chain hydrogen bond interactions as well as the high rigidity of the carbazole and oxadiazole moieties. The $T_{\mathrm{g}}$ of the PUs fell into the region of $135-178{ }^{\circ} \mathrm{C}$ and the $5 \%$ weight loss of the polymer $\left(T_{\mathrm{d}}\right)$ were all above $257^{\circ} \mathrm{C}$. In particular, CX01 showed a noticeably high $T_{\mathrm{d}}$ of $301^{\circ} \mathrm{C}$.

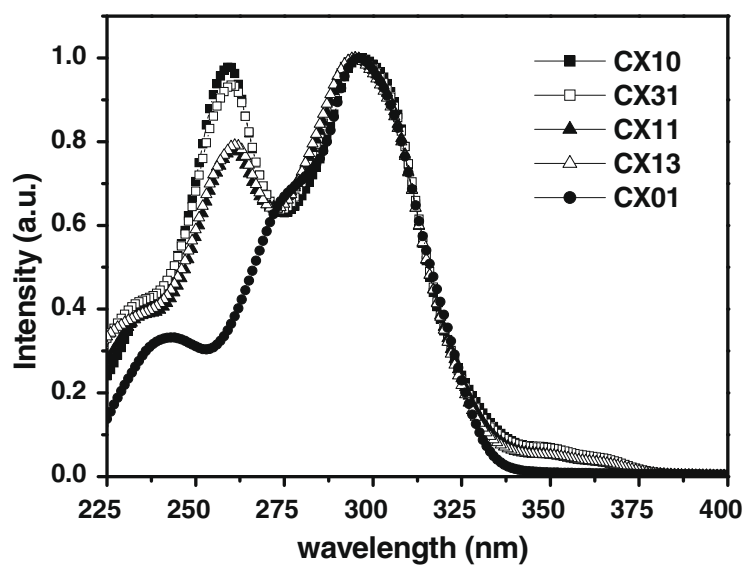

Fig. 2. UV spectra of the PU-polymers in THF: CX10 ( $)$ ); CX31 ( $\square$ ); CX11 $(\triangle)$; $\mathbf{C X 1 3}(\triangle)$; CX01 $(\bullet)$.

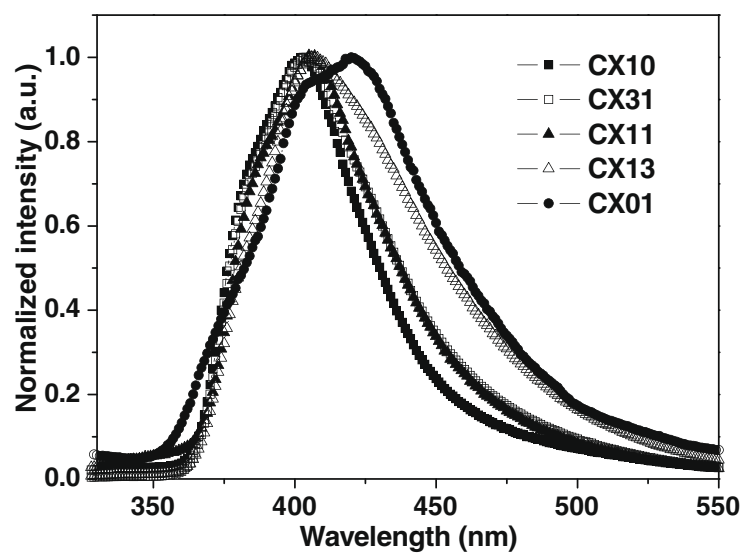

Fig. 3. PL spectra of PU co-polymers in solid film of CX10 (匹); CX31 ( $\square)$; CX11 (४); CX13 $(\triangle)$; CX01 $(\bullet)$.

\subsection{Photophysical properties of the PUs}

Normalized UV-Vis absorption and photo-luminescent spectra of the PUs in solution and solid thin-film were shown in Figs. 2 and 3. The photophysical data were summarized in Table 2. The UV-Vis absorption spectrum of CX10 showed two major absorption bands peaking at 260 and $300 \mathrm{~nm}$, and one weak absorption band at $340 \mathrm{~nm}$. When the weight of the OXD portion in the PU increased, the relative absorption intensities at 260 and $340 \mathrm{~nm}$ decreased and completely disappeared in the spectrum of CX01. On the other hand, CX01 showed a major absorption band at $300 \mathrm{~nm}$ and two other absorption bands at 240 and $270 \mathrm{~nm}$. No charge-transfer absorption band was observed in the spectra of CX31-CX13, indicating that charge transfer interactions between the carbazole and oxadiazole groups were insignificant. Similar observation was also obtained in the solid-film sample.

The photoluminescence (PL) of the thin film of CX10 showed the $\lambda_{\max (\mathrm{PL})}$ at around $400 \mathrm{~nm}$. On the other hand, the PL of CX01 showed emission peaking at $422 \mathrm{~nm}$. When comparing the spectra of CX10 and CX01, ones would perceive that both $\mathrm{Cz}$ and $\mathrm{OXD}$ fluorophores emitted in a similar region. In this situation, the Förster type energy transfer between two fluorophores would be poor due to mismatching of their absorption-emission spectra. Therefore, the emission spectra of CX31-CX13 were composed

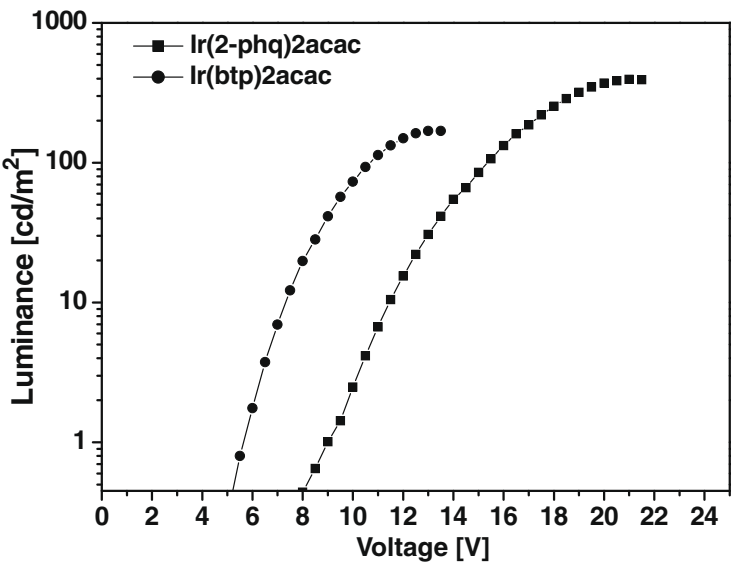

Fig. 4. The BV plots of the red color PLED device when CX31 as phosphorescent host: $\operatorname{Ir}(\text { btp })_{2}($ acac $)(\mathbf{\bullet}) ; \operatorname{Ir}(2-\text { phq })_{2}$ acac ( $)$.

Table 3

UV-visible absorption, photoluminescence properties, and the estimated HOMO-LUMO levels of CX10-CX01 in solid film.

\begin{tabular}{lllll}
\hline PU & $\lambda_{\text {absmax }}(\mathrm{nm})$ & $\lambda_{\text {PLmax }}(\mathrm{nm})$ & $E_{\text {gap }}(\mathrm{eV})$ & LUMO $(\mathrm{eV})$ \\
\hline CX10 & $296(303)^{\mathrm{a}}$ & $403(396 / 0.21)^{\mathrm{b}}$ & 3.45 & -1.83 \\
CX31 & $295(302)$ & $404(396 / 0.18)$ & 3.44 & -5.28 \\
CX11 & $295(300)$ & $406(396 / 0.51)$ & 3.52 & -5.28 \\
CX13 & $295(306)$ & $406(397 / 0.48)$ & 3.53 & -5.31 \\
CX01 & $296(305)$ & $420(399 / 0.40)$ & 3.71 & -1.79 \\
\hline
\end{tabular}

${ }^{\mathrm{a}}$ In the parentheses is noted the solution $\lambda_{\mathrm{absmax}}(\mathrm{nm})$

b In the parentheses is noted the solution $\lambda_{\mathrm{PLmax}}(\mathrm{nm})$ and the relative quantum yield by comparing against coumarin 1 in THF [47]. The concentration of the PU solutions was $10^{-5} \mathrm{~g} / \mathrm{mL}$ in THF. For the film preparation, PU solution $\left(10^{-2} \mathrm{~g} / \mathrm{mL}\right)$ was spin-coated onto a quartz plate with spin-rate of $2000 \mathrm{rpm}$ and was further dried with spurt nitrogen. 
of the emissions from the $\mathrm{Cz}$ and OXD units even in solid film. It is noteworthy to mention that many red-light emitting phosphorescent dyes would have weak bands at 400-500 nm that were assigned to spin-allowed ${ }^{1} \mathrm{MLCT}$ transitions and weaker absorption tails above $500 \mathrm{~nm}$, which are attributed to spin-forbidden ${ }^{3} \mathrm{MLCT}$ and ${ }^{3} \mathrm{LC}$ transitions $[48,49]$. In the present cases, the Cz-OXD PUs have fluorescent emission peaking at around $400 \mathrm{~nm}$ and tailing to $500 \mathrm{~nm}$. The good spectral overlap properties would be beneficial to the energy transfer process from the polymer matrix to the red-light emitters.

\subsection{Electrochemical behavior of the PUs}

The oxidation potential of CX10-CX01 was determined by cyclic voltammetry (CV) against ferrocene as the internal standard (Table 3). Since the PUs did not show reversible waves in their $\mathrm{CV}$ and $E_{1 / 2}$ could not be accurately determined, we adopted their onset potentials ( $\left.E_{\mathrm{ox}}^{\text {onset }}\right)$ for estimation of the HOMO energy level. The HOMO and LUMO levels were calculated according to an empirical formula of $E_{\mathrm{HOMO}}=-e\left(E_{\mathrm{ox}}^{\mathrm{onset}}+4.8\right)(\mathrm{eV}),[50]$ and $E_{\mathrm{LUMO}}=$ $E_{\mathrm{HOMO}}-E_{\mathrm{g}}$ in which $E_{\mathrm{g}}$ is the optical band gap. The value

a
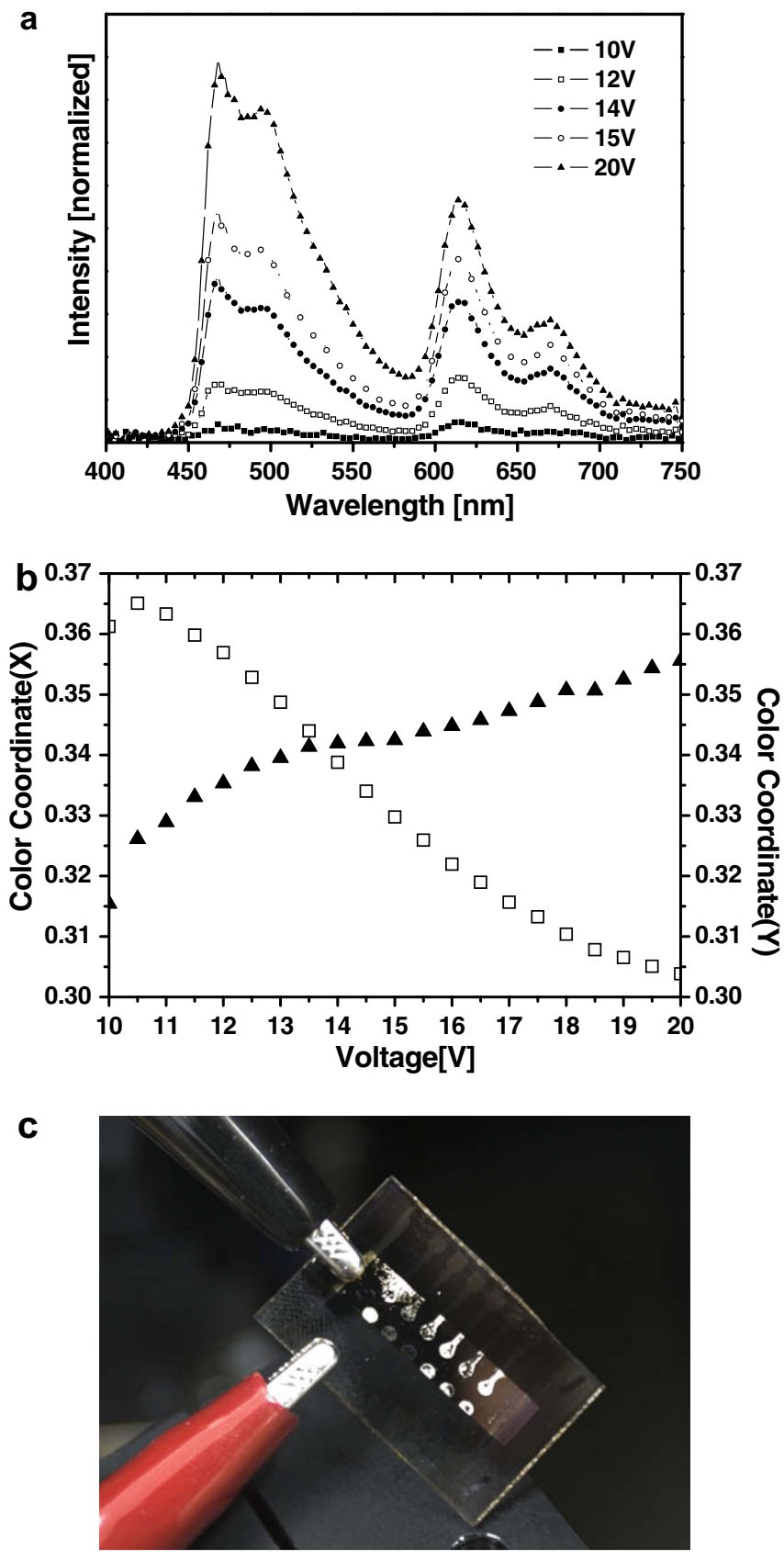

Fig. 5. The EL spectrum (top) of the white light emitting PLED device in different voltages, $10 \mathrm{~V}(\boldsymbol{\square}) ; 12 \mathrm{~V}(\square) ; 14 \mathrm{~V}(\boldsymbol{\bullet}) ; 15 \mathrm{~V}(\mathrm{O}) ; 20 \mathrm{~V}(\boldsymbol{\Delta})$. The plot shows the shift of the CIE coordinates along with increasing applied electrical voltage (middle). The PLED device shows write emission (bottom). 
of $E_{g}$ was estimated by using the equation of $E_{g}=1240 /$ $\lambda_{\text {onset of uv }}(\mathrm{eV})$. According to our estimation, their HOMO energy levels lies between 5.28 and $5.54 \mathrm{eV}$, which have good matching with that of ITO. The optical gaps of 3.44-3.71 eV for CX10-CX13 were calculated according to their spectral data. The LUMO levels of $1.78-1.84 \mathrm{eV}$ were accordingly derived.

\subsection{Surface analysis of the PU film on ITO surface}

High performance OLED devices usually require having the organic layers deposited onto a smooth ITO surface. Therefore, the roughness control of the ITO surface is essential for improving the OLED performance. Literature reported that spin-coating of a layer of conducting polymer such as PEDOT-PSS onto the ITO surface would significantly reduce this problem. In the present section, the surface conditions of the ITO substrate before and after PU modification were compared. The roughness of the surface was monitored by atomic force microscopy (AFM) using a non-contact Mac mode.

Before surface modification, there were many irregular prominences on the ITO surface. The original roughness r.m.s. (Root-mean-square) of ITO glass surface was $0.429 \mathrm{~nm}$. After spin-coating a layer of CX10, with the thickness of around $30 \mathrm{~nm}$ on top, the roughness dropped to $0.217 \mathrm{~nm}$. Contrary to the bare surface, the surface became more flat after CX10 modification. The height profile with good flatness has been observed.

\subsection{The use of CX31 as phosphorescent host in the light emitting layer}

Since the PUs have good charge-transport characters, we were interested in applying them as bipolar hosts for PLED. The CZ-OXD PU copolymer could be used in principle as host matrix for phosphorescent light emitting purpose, with balanced hole and electron transport properties [51-53]. To find the appropriate component ratio, PHOLED from CX10, CX31, and CX13 have been fabricated and compared. The device structure of ITO/PEDOTPSS(30 nm)/Ir complex (8\%) in PU (30 nm) /BCP(10 nm)/ $\mathrm{Alq}_{3}(40 \mathrm{~nm}) / \mathrm{LiF}(1 \mathrm{~nm}) / \mathrm{Al}(150 \mathrm{~nm})$ was adopted in these study. However, only CX31 was proved an effective host. When a red phosphorescent dye-dopant of bis(2-benzo[b]thiophen-2-yl-pyridine) (acetylacetonate) iridium, denoted as $\operatorname{Ir}(\text { btp })_{2}(\mathrm{acac})$, was used, the PHOLED device turned on at $5.7 \mathrm{~V}\left(1 \mathrm{~cd} / \mathrm{m}^{2}\right)$ with the highest brightness of $169 \mathrm{~cd} / \mathrm{m}^{2}$ (Fig. 4). The EL spectrum is identical with the PL of $\operatorname{Ir}(\mathrm{btp})_{2}(\mathrm{acac})$, with the peak emission at $615 \mathrm{~nm}$. When bis(2-phenylquinoline)(acetylacetonate) iridium(III), denoted as $\operatorname{Ir}(2-\mathrm{phq})_{2}$ acac, was used, the device turned on at $9 \mathrm{~V}\left(1.0 \mathrm{~cd} / \mathrm{m}^{2}\right)$ and reached the maximum brightness of $394 \mathrm{~cd} / \mathrm{m}^{2}$ at $21 \mathrm{~V}$ with the highest EL efficiency of $1.0 \mathrm{~cd} / \mathrm{A}$.

White phosphorescent light emitting device was composed by co-doping bis(3,5-difluoro-2-(2-pyridyl)phenyl(2-carboxypyridyl)iridium (FIrpic) and $\operatorname{Ir}(\text { btp) })_{2}$ (acac) in CX31 with the weight ratio of 2:5:80. The CIE shown was $(0.34,0.34)$ at $14 \mathrm{~V}$, which is very close to the pure white light CIE of $(0.33,0.33)$ (Fig. 5$)$. The brightness performance

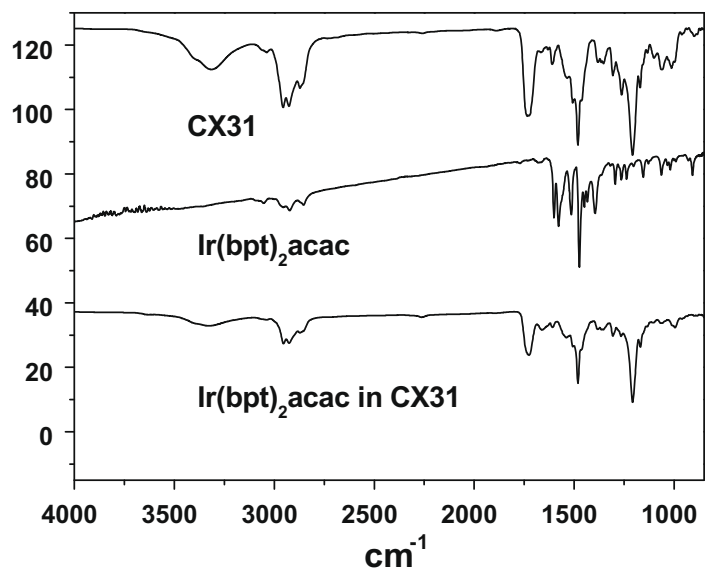

Fig. 6. The IR spectra of CX31, $\operatorname{Ir}(\mathrm{bpt})_{2} \mathrm{acac}$ and its blends for comparison.

with the device was $45 \mathrm{~cd} / \mathrm{m}^{2}$ and the turn on voltage was below $10 \mathrm{~V}$ with the maximum efficiency of $0.21 \mathrm{~cd} / \mathrm{A}$. However, the relative intensities of the blue and red changed slightly when the applied voltage increased.

To further understand whether there were any unusual polymer-Ir complexes interactions occurring in the light emitting matrix, the polymer-Ir complexes blend was subjected to IR analysis. Fig. 6 showed the IR spectra of CX31, $\operatorname{Ir}(\mathrm{bpt})_{2} \mathrm{acac}$, and their blending. The IR of CX31 showed strong absorptions at $3250-3500 \mathrm{~cm}^{-1}$ and $1650-$ $1700 \mathrm{~cm}^{-1}$ that were assigned to absorption of the $-\mathrm{NH}-$ and the $\mathrm{C}=\mathrm{O}$ stretching modes. No obvious new features were observed after $\operatorname{Ir}(\mathrm{bpt})_{2} \mathrm{acac}(8 \mathrm{wt} \%$ ) was mixed into the polymer matrix, indicating that the light emitting layer was composed of a physical blend of the PU and the Ir complexes.

\section{Discussion and conclusion}

The present work successfully demonstrated the use of PU based carbazole-oxadiazole co-polymers as host for PHOLED applications. To our knowledge, no example has been reported in this research direction. Although PUs are well known engineering polymeric materials with good mechanical properties, applications of PU on PLED are uncommon. Particularly, the applications of PU as the light emitting layer are very rare. This is probably due to the hydrogen bond quenching effects [54]. It has been reported that vibrational deactivation through hydrogen bond interactions between the protic environment and the fluorophore would facilitate the fluorescence quenching. For example, hydrogen bonding of Nile-Red, an important red-emission fluorescence dyes for laser and OLED applications, with alcohols occurred both in the ground state and the excited states [55]. The fluorescence quantum yield was significantly diminished with increasing hydrogen bond donating power of the medium.

Similar phenomena were reported on the arylnitrile derivatives [56]. The exceptionally efficient fluorescence quenching was observed for 4,-N,N-dimethylaminobenzonitrile (DMABN) in polar protic solvents. A mechanistic 
explanation based on the $\mathrm{CN} \cdots \mathrm{HO}$ configuration has recently been evidenced.

Similar effects were observed for arylamine derivatives. Significant quenching of the intramolecular charge separated state of $\mathrm{N}, \mathrm{N}$-dimethylaminophenylacetylene was observed in protic solvents, and both the triplet and fluorescence yields were much lower than those in aprotic polar solvents [57]. Again, radiationless relaxation through the vibrational modes of hydrogen bond complexation of $\mathrm{ArNMe}_{2} \cdots \mathrm{HO}$ has major contributions to the quenching process.

Since the PU systems formed from diisocyanate and diol contains polar protic - $\mathrm{NH}(\mathrm{CO})$ - components and many fluorescent dyes usually contain the hydrogen bond accepting groups such as nitrile, pyridyl, or amino groups, these observations lead to a suspicion on whether PU is an appropriate matrix for the light emitting layer. Ha reported the first attempt on using PU-DCM as the matrix for the red-emission PLED $[19,20]$. In these cases, the maximum brightness of the devices was $50-60 \mathrm{~cd} / \mathrm{m}^{2}$ (Red emission). We attributed the low brightness of the PLED devices to the radiationless deactivation of the exciton through of the hydrogen bond interactions. Chien has attempted using PU as the scaffold to tether oligo-PPV units and used them as fluorescent dopant in PVK-PBD for electroluminescent devices. In this situation, when the hydrogen bond array was highly diluted, $500 \mathrm{~cd} / \mathrm{m}^{2}$ of brightness (blue-green) could be reached [58]. In our cases, we adopted the carbazole-oxadiazole PUs as the bipolar host for phosphorescent OLED (PHOLED) and successfully demonstrated that it could be a good host for red PHOLED $\left(\sim 400 \mathrm{~cd} / \mathrm{m}^{2}\right.$, and $1 \mathrm{~cd} / \mathrm{A}$ ). The performance is one order of magnitude higher than the fluorescent system. Although radiationless relaxation would still be one of the major pathways for conversion of the triplet exciton back to the ground state, in particularly, for the red light emitters because of the lower energy gap that close to the IR region, our observations suggested that PU would still be one of the candidates for PLED applications.

The present research pioneered the work of using carbazole-oxadiazole based PUs as the phosphorescent host for PLED applications. The successful use of CX31 as the phosphorescent host for PLED, indicating that PUs can also be used as appropriate materials for the light emitting layer.

\section{Acknowledgment}

This work was supported by Ministry of Economic Affairs (grant no. 93-EC-17-A-08-S1-0015) and National Science Council of Taiwan (NSC 95-2113-M002-021-MY3), Academia Sinica (Thematic Project) and Advanced Polymer Nano-technology Research Center.

\section{References}

[1] Tang CW, Vanslyke SA. Appl Phys Lett 1987;51:913.

[2] Shirota Y, Kageyama H. Chem Rev 2007;107:953.

[3] Burroughes JH, Bradley DDC, Brown AR, Marks RN, Mackay K, Friend $\mathrm{RH}$, et al. Nature 1990;347:539.

[4] Braun D, Heeger AJ. Appl Phys Lett 1991;58:1982.
[5] Lee YZ, Chen X, Chen SA, Wei PK, Fann WS. J Am Chem Soc $2001 ; 123: 2296$.

[6] Huang TH, Jiann T, Lin JT, Chen LY, Lin YT, Wu CC. Adv Mater 2006; $18: 602$.

[7] Randall D, Lee S, editors. The polyurethanes book. New York: Wiley 2002.

[8] Li Y, Kang W, Stoffer JO, Chu B. Macromolecules 1994;27:612.

[9] Suresh KI, Kishanprasad VS. Ind Eng Chem Res 2005;44:4504.

[10] Green RJ, Corneillie S, Davies J, Davies MC, Roberts CJ, Schacht E, et al. Langmuir 2000;16:2744.

[11] Hasegawa M, Ikawa T, Tsuchimori M, Watanabe O, Kawata Y. Macromolecules 2001;34:7471.

[12] Crenshaw BR, Weder C. Macromolecules 2006;39:9581.

[13] Njuguna J, Pielichowski K. J Mater Sci 2006;39:4081.

[14] Wang YZ, Hsu YC, Chou LC, Hsieh KH. J Polym Res 2004;11:127.

[15] Sanjai B, Raghunathan A, Natarajan TS, Rangarajan G. Phys Rev B 1997;55:10734.

[16] Kuo CH, Peng KC, Kuo LC, Yang KH, Lee JH, Leung Mk, et al. Chem Mater 2006;18:4121.

[17] $\mathrm{Ku} \mathrm{CH}$, Kuo $\mathrm{CH}$, Chen $\mathrm{CY}$, Leung Mk, Hsieh $\mathrm{KH}$. J Mater Chem 2008;18:1296.

[18] Lin KR, Kuo CH, Kuo LC, Yang KH, Leung Mk, Hsieh KH. Eur Poly J 2007;43:4279.

[19] Lim H, Noh JY, Lee GH, Lee SE, Jeong H, Lee K, et al. Thin Solid Films 2000;363:152.

[20] Jeong H, Zou D, Tsutsui T, Ha CS. Thin Solid Films 2000;363:279.

[21] Li M, Daniels ES, Dimonie V, Sudol ED, El-Aasser MS. Macromolecules 2005;38:4183.

[22] Ishii H, Hayashi N, Ito E, Washizu Y, Sugi K, Kimura Y, et al. Phys Stat Sol (A) 2004;201:1075.

[23] Ishii H, Sugiyama K, Ito E, Seki K. Adv Mater 1999;11:605.

[24] Deepa P, Jayakannan M. J Polym Sci Polym Chem 2008;46:5897.

[25] Aoki A, Tamagawa Y, Miyashita T. Macromolecules 2002;35:3686.

[26] Kimoto A, Cho JS, Higuchi M, Yamamoto K. Macromolecules 2004;37:5531.

[27] Lu J, Tao Y, D'iorio M, Li Y, Ding J, Day M. Macromolecules 2004;37:2442.

[28] Hwang SW, Chen Y. Macromolecules 2002;35:5438.

[29] You Y, Kim SH, Jung HK, Park SY. Macromolecules 2006;39:349.

[30] Jiang J, Jiang C, Yang W, Zhen H, Huang F, Cao Y. Macromolecules 2005;38:4072.

[31] Xin Y, Wen GA, Zeng WJ, Zhao L, Zhu XR, Fan QL, et al. Macromolecules 2005;38:6755.

[32] Wu CW, Tsai CM, Lin HC. Macromolecules 2006;39:4298.

[33] Zhan X, Liu Y, Wu X, Wang S, Zhu D. Macromolecules 2002;35:2529.

[34] Peng Z, Zhang J. Chem Mater 1999;11:1138.

[35] Kim JH, Park JH, Lee H. Chem Mater 2003;15:3414.

[36] Lee DW, Kwon KY, Jin JI, Park Y, Kim YR, Hwang IW. Chem Mater $2001 ; 13: 565$.

[37] Blochwitz J, Hofmann PM, Leo MK. Synth Met 2002;127:169.

[38] Zhu Y, Rabindranath AR, Beyerlein T, Tieke B. Macromolecules 2007:40:6981.

[39] Paliulis O, Ostrauskaite J, Gaidelis V, Jankauskas V, Strohriegl P. Macromol Chem Phys 2003;204:1706.

[40] Pan X, Liu S, Chan HSO, Ng SC. Macromolecules 2005;38:7629.

[41] Lau CK, Belanger PC, Dufresne C, Scheigetz J, Therien M, Fitzsimmons B, et al. J Med Chem 1992;35:1299.

[42] Connell JW, Hergenrother PM, Wolf P. Polymer 1992;33:3507.

[43] Mehta R, Dadmun MD. Macromolecules 2006;39:8799.

[44] Viswanathan S, Dadmun MD. Macromolecules 2002;35:5049.

[45] Liu Z, Wu X, Yang X, Liu D, Jun C, Sun R, et al. Biomacromolecules 2005;6:1713.

[46] Chiang LY, Wang LY, Kuo CS. Macromolecules 1995;28:7574.

[47] Rusalov MV, Druzhinin SI, Uzhinov BM. J Fluorescence 2004;14: 193. The quantum yield of coumarin 1 in THF is 0.85 . For reference, see.

[48] Xu Y, Guan R, Jiang J, Yang W, Zhen H, Peng J, et al. J Polym Sci Part A: Polym Chem 2007;46(2):453.

[49] Zhao Q Jiang C, Shi M, Li FY, Yi T, Cao Y, et al. Organometallics 2006;25(15):3631.

[50] Liu MS, Jiang X, Liu S, Herguth P, Jen AKY. Macromolecules 2002;35:3532.

[51] Xia H, Zhu Y, Lu D, Li M, Zhang C, Yang B, et al. J Phys Chem B 2006;110:18718

[52] Carlson B, Phelan GD, Kaminsky W, Dalton L, Jiang X, Liu S, et al. J Am Chem Soc 2002;124:14162.

[53] Hwang FM, Chen HY, Chen PS, Liu CS, Chi Y, Shu CF, et al. Inorg Chem 2005;44:1344. 
[54] (a) Prasanna de Silva A, Nimal Gunaratne HQ Gunnlaugsson T, Huxley AJM, McCoy CP, Rademacher JT, et al. Chem Rev 1997;97:1515. For other examples, see;

(b) Martin MM, Bréhéret E. J Phys Chem 1982;86:107;

(c) Zhao GJ, Han KL. J Phys Chem A 2007;111:9218.

[55] Nagy K, Biczik L. Magyar Kemiai Folyoirat, Kemiai Kozlemenyek 2004;109-110(1):29-33.
[56] (a) Köhler G, Grabner G, Rotkiewicz K. Chem Phys 1993;173:275;

(b) Pál K, Kállay M, Köhler G, Zhang H, Bitter T, Kubinyi M, et al. Chem Phys Chem 2007;8:2627.

[57] Hirata Y, Okada T, Nomoto T. J Phys Chem A 1998;102:6585.

[58] Blumstengel S, Sokolik I, Dorsinville R, Voloschenko D, He M, Lavrentovich O, et al. Synth Met 1999;99:85. 